\title{
Midwives and Nurses Compliance with Standard Precautions in Palestinian Hospitals
}

\author{
Imad Fashafsheh ${ }^{*}$, Ahmad Ayed ${ }^{2}$, Mahdiah Koni' ${ }^{3}$, Safaa Hussein ${ }^{1}$, Imad Thultheen $^{1}$ \\ ${ }^{1}$ AL-Farabi Colleges, Dentistry-Medicine-Nursing, Riyadh, KSA \\ ${ }^{2}$ Department of Nursing, Arab American University, Jenin, Palestine \\ ${ }^{3}$ Department of Nursing, An-Najah National University, Nablus, Palestine \\ Email: *fashafsheh@gmail.com
}

Received 6 November 2015; accepted 19 April 2016; published 22 April 2016

Copyright (C) 2016 by authors and Scientific Research Publishing Inc.

This work is licensed under the Creative Commons Attribution International License (CC BY). http://creativecommons.org/licenses/by/4.0/

(c) (i) Open Access

\section{Abstract}

Midwives and nurses should use the standard precautions as the basic level of infection control precautions when delivering care to all patients, regardless of their presumed infection status. Therefore midwifes and nurses should have sound knowledge and compliance with standard precaution. Aim of the study: The study aimed to assess the level of the compliance of standard precautions among the midwives and nurses in the Palestinian Hospitals. Method: A cross sectional study was conducted from May to June 2015 on 81 midwives and nurses from Palestinian hospitals. The data were collected from labor rooms and postpartum departments of Palestinian hospitals. Data were collected using pretested questionnaire on 81 midwives and nurses selected by convenience sample. Results: The current study showed that the average of standard precautions knowledge level and compliance are $74.6 \%$ and $83.8 \%$ respectively. There are an association between age, education, work experience, and compliance with standard precautions at $p<0.05(0.000,0.031$, and 0.043$)$ respectively. At the same time no significant association between training courses and compliance to standard precautions at $p<0.05(0.191)$. Conclusion: The midwives and nurses in the current study for both knowledge and compliance have high level regarding standard precautions. There is an association between age, education, work experience, and compliance with standard precautions. Recommendations: Knowledge of midwives and nurses should be updated; the importance of latest evidence-based practices of infection control in continuing education/training program should be emphasized; and training programs for newly midwives and nurses about standard precaution and at regular intervals should be provided.

"Corresponding author.

How to cite this paper: Fashafsheh, I., Ayed, A., Koni, M., Hussein, S. and Thultheen, I. (2016) Midwives and Nurses Compliance with Standard Precautions in Palestinian Hospitals. Open Journal of Nursing, 6, 294-302. 


\section{Keywords}

\section{Nurses, Midwives, Compliance, Standard Precautions}

\section{Introduction}

Health care workers are constantly exposed to various microorganisms which caused for them serious or even lethal infections [1]. Increased infant mortality in developing countries resulted from hospital acquired infections which is one of the main causes as some studies have shown [2].

Statistics reported by World Health Organization (WHO), 1,400,000 people suffer from complications related to HAI. The rate of preventable hospital acquired infections in developing countries due to medical care is estimated to be about $40 \%$ or above [3]. Nosocomial infections, such as endometritis, postoperative pelvic infection, urinary tract infections, neonatal sepsis, etc., are serious complications in normal vaginal delivery.

The incidence of postoperative infections approaches 38\%. Surgical site infection which is the third most common nosocomial infection includes obstetrics and gynecological sources [4]. An understanding of the fundamentals of the host, surgical risk factors and vaginal flora can aid in prevention of postoperative infections which result in significant morbidity and mortality [4].

It has been reported that the risk of health care-associated infection is 2 to 20 times higher in developing countries in comparison with developed countries and 5\% to $10 \%$ of patients admitted to hospitals in developed countries acquire these infections (WHO, 2008) [5].

Infection control measures include appropriate hand hygiene and the correct application of basic precautions during invasive procedures are simple and of low-cost, but need health staff accountability and behavioral change, in addition to improve staff education, reporting and surveillance systems [6].

The human element stays the efficient role in increasing or decreasing the chances of catching HCAI [7]. Healthcare workers compliance with standard precautions has been recognized as an important means to prevent and control health care-associated infections in patients and health workers [8].

Standard precautions are defined as a set of infection prevention practices that apply to all patients, regardless of suspected or confirmed diagnosis or presumed infection status [9]. These precautions considered the basic level of infection control precautions which are to be used, as a level of precautions [10].

Standard precautions are recommended when delivering the care to all clients, regardless of their health condition. It is also recommended that when handling equipment and instruments are contaminated or suspected of contamination, and in situations of contact risk with body fluids, blood, secretions and excretions except sweat, without considering the presence or absence of visible blood and skin with solution of continuity and mucous tissues. They included precautions against agents that are transmitted by the following routes of transmission: droplet, air-borne, and contact routes [10] [11].

Standard precautions aim to prevent and/or reduce transmission of HAI, and, at the same time, to protect nurses from sharp injuries. These aims can be achieved by the application of standard precaution measures which consist of the following elements: hand hygiene, prevention of sharp injuries, and personal protective equipment (gloves, gown, gaggle, facemasks, head protection, foot protection and wearing face shields) [10].

Nurses are often exposed to several infections during the course of carrying out their nursing tasks [12]. Nosocomial infection or Health-care-associated infection (HCAI) refers to infection that is acquired during hospitalization, the process of care and not manifested at the time of admission to a hospital or other health-care facility [13].

Nurses and midwives are directly worked with patient and susceptible to acquire infections from patients especially blood borne diseases. It has been estimated that more than 170 million people worldwide are infected with Hepatitis C and about 40 million are living with HIV/AIDS [14].

The critical role of nurses in patient care emphasis on the role of the control hospital acquired infections. So the nurses are the key members of infection control team in hospitals. Therefore, nurses should have good knowledge and skills in the field of infection control [15].

As revealed from evidence, the proper compliance with Standard Precautions can protect health care workers from various kinds of Occupational Blood Exposure, Hospital Acquired Infections including pneumonia and 
intravascular catheter infections [16]. [17] presumed that 38.2\% had fair knowledge of standard precaution, and 77(37.8\%) had good knowledge. However $24.0 \%$ of the studied sample had poor knowledge level. According to their compliance $52.9 \%$ had fair level, $45.6 \%$ had good level and only $1.5 \%$ had poor level.

A study conducted by [18] about hand hygiene among health care staff noted that nurses' knowledge about standard precautions is insufficient and many of them believed that by wearing gloves no need for washing hands). Another study results revealed that only $43 \%$ of nurses had a good knowledge in this regard [19]. A descriptive and cross-sectional study conducted by [20] reported that the participants have an acceptable level of knowledge regarding hand hygiene. The work experience and history of previous training were the most important predictors of participants' knowledge about hand hygiene.

A cross sectional study conducted among nurses in governmental hospitals of Palestine revealed that, around half of the subjects had fair knowledge level and the most of them had good practice level of infection control [21].

\section{Subjects and Method}

\subsection{Aim of the Study}

The study aimed to assess the level of the compliance of standard precautions among the midwives and nurses in the hospitals of Palestine.

\subsection{Research Questions}

The following three research questions were formulated to achieve the aim of the current study:

1. What are levels of midwives' and nurses' knowledge about the standard precautions at the selected Palestinian hospitals?

2. What are levels of midwives' and nurses' compliances of the standard precautions at the selected Palestinian hospitals?

3. Are there relationship between the standard precautions knowledge and compliance with age, gender, education, years of experience, and training course on standard precautions?

\subsection{Research Design}

It is a descriptive, cross-sectional study.

\subsection{Study Setting}

The data were collected from labor rooms and postpartum departments of Palestinian hospitals, eight of them governmental (Alia hospital in Hebron city, Al Husain hospital in Beit Jala, and Abu Al Hassan hospital in Yatta, Rafedia in Nablus city, Thabet Thabet $\mathrm{n}$ Tulkarm city, Khaleel Solaiman in Jenin city, Darweesh Nassal in Qalqellia city, and Yaser Arafat in Salfit city) and three private hospitals (Al-Ahli Hospital in Hebron city, Al Mizan Hospital in Hebron city, and Arab Society hospital in Bethlehem city)

\subsection{Study Period}

The study was conducted from May to June 2015 in the targeted hospitals.

\subsection{Study Sample}

A convenience sample includes 81 midwives and nurses.

\subsection{The Inclusion Criteria}

Palestinian midwives or nurses who work in the selected departments of the targeted hospitals with full time employment.

\subsection{Tool of the Study}

A self-administrative questionnaire was developed by researchers and used to assess: 
a) Socio-demographic characteristics of subjects consist of age, marital status, Hospital, Qualification, Department of work, working experience, Special sharps disposal box in your department, Hepatitis B vaccine, and Infection control training course.

b) Subjects' knowledge consists of 32 items, each item had a group of answer points, one point was awarded for correct answer; incorrect or I don't know answer took zero. The correct responses were summed up to get a total knowledge scores for each participant. Total score for all questions reached 32 grades and transformed to $100 \%$.

c) Compliance consist of 23 items using a 3-item Likert scale (every time (3), sometime (2), and never (1)). The compliance scores were summed up to get total scores and transformed to $100 \%$.

\section{Validity and Reliability of the Study}

To assure the content validity of the questionnaire, it was revised and validated by panel of 5 experts in academic and health field; they agreed and no comments. Internal consistency among the questionnaire items was assessed 0.88 Cronbach's alpha $(\alpha)$ and it was considered acceptable.

\section{A Pilot Study}

Ten midwives from the labor department of Nablus special hospital as a pilot study was included to assess the clarity of the questions, effectiveness of instructions, completeness of response sets, time required to complete the questionnaire and success of data collection technique. Pilot subjects were asked to comment on the applicability and appropriateness (validity) of the questionnaire. All questions were answered no clarity of questions were required. Then, the researchers determined that it would take 20 minutes to complete the questionnaire.

\section{Ethical Considerations}

This study was approved by the nursing department, Arab American University. This emphasized by MOH agreement with their permission for the investigators to utilize the targeted hospitals. Approval from midwives and nurses were obtained. Several strategies were utilized to protect the nurse's rights who agreed to participate in this study. First, oral verbal consent of the midwives and nurses was obtained prior to the administration of the questionnaire. The midwives and nurses were informed of the purpose of the study, and that they had the right to refuse to participate. Also the voluntary nature of participation was stressed as well as confidentiality. Furthermore, the midwives and nurses were told that they can refrain from answering any questions and they can terminate at any time. Anonymity of them was maintained at all times.

\section{Results}

Table 1 presents demographic characteristics of the studied sample. It clarifies that the majority of the studied nurses 64 (79.04\%) were in the age group of 20 - 30 years, and 57 (70.4\%) had bachelor degree. However, around two thirds $52(64.2 \%)$ were single, and $53(65.4 \%)$ had less than five years of experience. All of the samples assured that they have sharp box 81 (100.0\%). Regarding attendance of training courses, the most of the studied sample 70 (86.4\%) were received training course about infection control and 77 (95.1) had vaccinated against hepatitis $\mathrm{B}$.

Table 2 presents the knowledge and compliance mean of the universal precautions among midwives and nurses in the targeted settings. It clarified that the knowledge mean was $74.57 \%$ while compliance mean was 83.8\%. Hand washing knowledge and compliance items had the highest mean $91.8 \%$ and $86 \%$ respectively while the knowledge about infection microorganisms had the lowest mean 56.9\%. At the same time, both sharp box and needle using compliance items had the lowest mean according to universal precautions compliance $78.2 \%$.

Table 3 shows percentage distribution of the participants according to their knowledge and compliance of standard precautions. It clarifies that around half of the participants 40 (49.4.0\%) had fair knowledge level, 33 (40.7\%) had good knowledge, and 8 (9.9\%) had poor knowledge level. On the other hand, it indicated that two thirds of the participants 51 (63.0\%) had good compliance, 27 (33.3\%) had fair compliance, and the rest 3 (3.7\%) had poor compliance.

Table 4 shows a comparison between the mean of the knowledge scores and the socio-demographic characteristics of the studied sample. It displays that high mean knowledge scores were found among those who were at 
Table 1. Assessment of the socio-demographic and characteristics of the sample.

\begin{tabular}{|c|c|c|c|}
\hline Parameters & & No. & $\%$ \\
\hline \multirow[t]{3}{*}{ Age } & 20 - 30 years old & 64 & 79.0 \\
\hline & 31 - 40 years old & 10 & 12.3 \\
\hline & More than 40 & 7 & 8.6 \\
\hline \multirow[t]{3}{*}{ Education } & Nursing diploma & 21 & 25.9 \\
\hline & Bachelor & 57 & 70.4 \\
\hline & Master & 3 & 3.7 \\
\hline \multirow[t]{2}{*}{ Marital status } & Single & 52 & 64.2 \\
\hline & Married & 29 & 35.8 \\
\hline \multirow[t]{2}{*}{ Department } & Labor room & 52 & 64.2 \\
\hline & Post partum ward & 29 & 35.8 \\
\hline \multirow[t]{3}{*}{ Experience } & 5 years or less & 53 & 65.4 \\
\hline & 6 - 15 years & 18 & 22.2 \\
\hline & more than 15 years & 10 & 12.3 \\
\hline \multirow[t]{2}{*}{ Sharp box } & Yes & 81 & 100.0 \\
\hline & No & 0 & 00.0 \\
\hline \multirow[t]{2}{*}{ Training course } & Yes & 70 & 86.4 \\
\hline & No & 11 & 13.6 \\
\hline \multirow[t]{2}{*}{ Hepatitis B vaccine } & Yes & 77 & 95.1 \\
\hline & No & 4 & 4.9 \\
\hline
\end{tabular}

Table 2. Assessment of the knowledge and compliance of the universal precaution among midwives and nurses.

\begin{tabular}{|ccccccc}
\hline \multicolumn{7}{c}{ Knowledge and compliance mean of universal precautions } \\
$\begin{array}{c}\text { Universal precautions } \\
\text { Knowledge }\end{array}$ & $\mathbf{N}$ & Mean & Std. Deviation & $\begin{array}{c}\text { Universal precautions } \\
\text { compliance }\end{array}$ & Mean & Std. deviation \\
\hline Hand washing & 81 & 91.8210 & 11.71946 & Hand washing & 86.0082 & 15.34399 \\
Wearing gloves & 81 & 58.8477 & 19.73548 & Wearing gloves & 85.9259 & 17.70122 \\
Needles using & 81 & 77.7778 & 19.00292 & Needle using & 78.1893 & 20.96767 \\
Sharp box & 81 & 74.0741 & 35.45341 & Sharp box & 78.1893 & 23.07024 \\
Medical waste disposing & 81 & 82.2222 & 29.83287 & Gown and mask & 80.4527 & 21.04726 \\
Gown and mask & 81 & 82.0988 & 31.92632 & Total compliance & $\mathbf{8 3 . 8 0 7 5}$ & $\mathbf{1 5 . 7 8 7 7 8}$ \\
$\begin{array}{c}\text { Knowledge about } \\
\text { infectious microorganisms }\end{array}$ & 81 & 56.9959 & 32.36770 & & & \\
Total knowledge & $\mathbf{8 1}$ & $\mathbf{7 4 . 5 7 5 6}$ & $\mathbf{1 2 . 7 0 1 0 5}$ & & &
\end{tabular}

Table 3. Assessment of the midwives and nurses knowledge and compliance level of universal precautions.

\begin{tabular}{cccc}
\hline & & levels of standard precautions & \\
\hline Item & Poor & Fair & Good \\
\hline Knowledge & $8(9.9 \%)$ & $40(49.4 \%)$ & $33(40.7 \%)$ \\
Compliance & $3(3.7 \%)$ & $27(33.3 \%)$ & $51(63.0 \%)$ \\
\hline
\end{tabular}


Table 4. The relationship between the age, education, experience, and training course of the midwives and the nurses towards the knowledge of universal precautions.

\begin{tabular}{|c|c|c|c|c|c|c|}
\hline Items & & $\mathbf{N}$ & Mean & Std. deviation & $\mathbf{F}$ & Sig \\
\hline \multirow[t]{3}{*}{ Age } & 20 - 30 years old & 64 & 74.7559 & 12.21532 & \multirow{3}{*}{1.607} & \multirow{3}{*}{0.207} \\
\hline & 31 - 40 years old & 10 & 78.4375 & 7.13371 & & \\
\hline & More than 40 & 7 & 67.4107 & 20.55996 & & \\
\hline \multirow[t]{3}{*}{ Education } & Diploma & 21 & 72.7679 & 12.30881 & \multirow[t]{2}{*}{1.801} & \multirow[t]{2}{*}{0.172} \\
\hline & Bachelor & 57 & 74.5614 & 12.89064 & & \\
\hline & Master & 3 & 87.5000 & 0.00000 & \multirow{4}{*}{0.895} & \multirow{4}{*}{0.413} \\
\hline \multirow[t]{3}{*}{ Experience } & 5 years or less & 53 & 75.9434 & 10.28414 & & \\
\hline & $6-15$ years & 18 & 72.2222 & 14.96353 & & \\
\hline & Above 15 years & 10 & 71.5625 & 19.17629 & & \\
\hline \multirow[t]{2}{*}{ Training course } & Yes & 70 & 75.3125 & 12.15733 & \multirow{2}{*}{1.751} & \multirow{2}{*}{0.190} \\
\hline & No & 11 & 69.8864 & 15.57948 & & \\
\hline
\end{tabular}

the age group of 31 - 40 years, master degree, had years of experience 5 years or less, and had attended training courses with means of $(78.4375,87.5000,75.9434$, and 75.3125$)$ respectively. No significant statistical differences were found in mean knowledge scores in relation to age, education, experience, and training course $(\mathrm{F}=$ $1.607,1.801,0.895$, and 1.751$)$ at $p<0.05(0.207,0.172,0.895$, and 0.190$)$ respectively.

Table 5 shows the comparison of mean compliance scores in relation to socio-demographic characteristics of the studied sample. It displays that high mean practices scores were found among those who were at the age group 20 - 30 years old, bachelor degree, had years of experience 5 years or less, and attended training courses with means of $(87.6585,86.6260,86.9292$, and 84.7205$)$ respectively. No significant statistical differences were found between mean practice scores towards training course $(\mathrm{f}=1.740)$ at $p<0.05(0.191)$. At the same time, significant statistical differences were found between mean practice scores towards age, education, and experience ( $\mathrm{f}=14.294,3.620$, and 3.276$)$ at $p<0.05(0.000,0.031$, and 0.043$)$ respectively.

Table 6 shows that there was significant statistical difference found between knowledge and compliance of standard precautions of the studied sample $(\mathrm{t}=4.590)$ at $p<0.05(0.000)$.

\section{Discussion}

Hospital acquired infection is a common problem all over the world. Therefore, up to date knowledge and nurses midwives skills can play important roles in standard precautions. Midwives and nurses should have the opportunity to practice standard precautions on a day-to-day basis as an integral part of patients' care. The outcome of this study showed that the average of the knowledge level with standard precaution among the midwives and nurses was $74.6 \%$. The finding of this study is different from [21] which revealed that knowledge level rate of standard precaution by nurses is around $54 \%$ in Palestine.

According to the compliance with standard precaution among the midwives and nurses the average was $83.8 \%$. It could be said from this result that the level of compliance with standard precaution is high. This may due to the work climate of the hospitals. This finding consistent with [22] study which discovered that promotion of safety climate often time leads to compliance to standard precaution. Another study, [23] supports these finding which reported that wearing of sterile surgical gloves by health workers is very conducive for the patient and for the protecting against occupational risk caused by blood borne infections from patients as well as cross-infection. Also, this finding is in line with the work of [21] which showed that the majority of the Palestinian midwives and nurses had good practice towards infection control. The finding of this study is inconsistent with [24] which revealed that compliant rate of standard precaution by nurses is less than $38 \%$ in London.

The findings of the study revealed that the average of the knowledge level of hand washing, wearing gloves, needle using, sharp box, medical waste disposing, gown and mask, and knowledge about infection microorganisms 
Table 5. The relationship between the midwives and nurses age, education, experience, and training course towards the compliance of universal precautions.

\begin{tabular}{|c|c|c|c|c|c|c|}
\hline Items & & $\mathbf{N}$ & Mean & Std. deviation & $\mathbf{F}$ & Sig \\
\hline \multirow[t]{3}{*}{ Age } & 20 - 30 years old & 64 & 87.6585 & 12.33539 & & \\
\hline & 31 - 40 years old & 10 & 63.4783 & 21.95598 & 14.294 & 0.000 \\
\hline & More than 40 & 7 & 77.6398 & 10.54614 & & \\
\hline \multirow[t]{3}{*}{ Education } & Diploma & 21 & 76.1215 & 20.45286 & 3.620 & 0.031 \\
\hline & Bachelor & 57 & 86.6260 & 13.28288 & & \\
\hline & Master & 3 & 84.0580 & 0.00000 & & \\
\hline \multirow[t]{3}{*}{ Experience } & 5 years or less & 53 & 86.9292 & 12.35483 & 3.276 & 0.043 \\
\hline & 6 - 15 years & 18 & 78.9050 & 23.73723 & & \\
\hline & Above 15 years & 10 & 76.0870 & 9.88274 & & \\
\hline \multirow[t]{2}{*}{ Training course } & Yes & 70 & 84.7205 & 15.78504 & & \\
\hline & No & 11 & 77.9974 & 15.22523 & 1.740 & 0.191 \\
\hline
\end{tabular}

Table 6. The relationship between the midwives and nurses knowledge and compliance of universal precautions.

\begin{tabular}{ccccccc}
\hline Item & Mean & N & Std. deviation & t & df & Sig. \\
\hline knowledge & 74.5756 & 81 & 12.70105 & 4.590 & 80 & 0.000 \\
Compliance & 83.8075 & 81 & 15.78778 & & & \\
\hline
\end{tabular}

were (92\%, 59\%, 78\%, 74\%, 82\%, 82\%, and 56\%) respectively. The implication of this finding is that the knowledge level of the standard precautions is well in hospital settings except the knowledge of microorganisms which need more attention on it.

It was observed from the findings that the midwives and nurses adhered strictly to the use of the standard precautions of hand washing, wearing gloves, needle using, sharp box, gown and mask (86\%, 86\%, 87\%, 78\%, and $80 \%$ ) respectively. The implication of this finding is that the use of the standard precautions of hand washing is well established in the clinical and hospital settings. This is in line with the previous findings of [25] that compliance on the part of healthcare workers with standard precautions has been recognized as an efficient means to prevent and control health care-associated infections in patients and health workers.

Lastly, the outcome of this study revealed an association between age, education, work experience, and compliance with standard precautions. At the same time no significant association between training courses and compliance with standard precautions. This may due to that these training courses not specific for standard precaution.

\section{Conclusion}

Knowledge and compliance of standard precaution of midwives and nurses cannot be neglected as it has proved to be of great importance as they are susceptible to different infection and diseases when precautious measures are not properly. Based on the findings of this study, it can be concluded that midwives and nurses in the current study for both knowledge and compliance have high level regarding standard precautions. There is an association between age, education, work experience, and compliance with standard precautions.

\section{Recommendations}

The study recommends

- Keep updating knowledge and compliance of midwives and nurses according standard precaution through continuing in-service educational programs. 
- Emphasizing the importance of the latest evidence-based practices of infection control in continuing education/training programs.

- Training programs for newly nurses and midwives according standard precautions and must be at regular intervals.

- This study should be replicated using observation checklist to assess the level of compliance.

\section{Acknowledgements}

The authors would like to express their sincere gratitude to the hospitals administrating team who helped in facilitating conduction of this study. Great appreciation as well is to the midwifery and nursing staff who accepted to participate in the current study.

\section{References}

[1] Twitchell, K.T. (2003) Blood Borne Pathogens. What You Need to Know—Part II. AAOHNJ, 51, 89-97.

[2] Huis, A., Hulscher, M., Adang, E., Grol, R., van Achterberg, T. and Schoonhoven, L. (2013) Cost-Effectiveness of a team and Leaders-Directed Strategy to Improve Nurses' Adherence to Hand Hygiene Guidelines: A Cluster Randomised Trial. International Journal of Nursing Studies, 50, 518-526. http://dx.doi.org/10.1016/j.jjnurstu.2012.11.016

[3] World Health Organization (2014) Improved Hand Hygiene to Prevent Health Care Associated Infections. http://www.who.int/gpsc/tools/faqs/evidence hand hygiene/en/2014

[4] Faro, C. and Faro, S. (2008) Postoperative Pelvic Infections. Infectious Disease Clinics of North America, 22, $653-663$. http://dx.doi.org/10.1016/j.idc.2008.05.005

[5] World Health Organization (2008) The First Global Patient Safety Challenge: “Clean Care Is Safer Care”. WHO, Geneva. http://www.who.int/gpsc/background/en/index.html

[6] Boullègue, O., Naija, W., Said, H., Nouria, A., Jaidane, N., Dhidah, L. and Boujaafar, N. (2013) Incidence of ICU Acquired Nosocomial Infections in University Hospital of Sahloul (Sousse-Tunisia). Antimicrobial Resistance and Infection Control, 2, 233.

[7] Cole, M. (2007) Infection Control: Worlds apart Primary and Secondary Care. British Journal of Community Nursing, 12, 301, 303-306.

[8] Garner, J.S. (1996) Guideline for Isolation Precautions in Hospitals. The Hospital Infection Control Practices Advisory Committee. Infection Control and Hospital Epidemiology, 17, 53-80.

[9] Center of Disease Prevention and Control (CDC) (2012) Glossary of Terms .Atlanta, USA.

[10] Center of Disease Prevention and Control CDC (2007) Guideline for Isolation Precautions: Preventing Transmission of Infectious Agents in Healthcare Settings. US, 136 p. http://www.cdc.gov/hicpac/pdf/isolation/isolation2007.pdf

[11] Vaz, K., McGrowder, D., Lindo, R.A, Gordon, L., Brown, P. and Irving, R. (2010) Knowledge, Awareness and Compliance with Universal Precautions among Health Care Workers at the University Hospital of the West Indies, Jamaica. International Journal of Occupational and Environmental Health, 1, 171-181.

[12] Kosgeroglu, N., Ayranci, U., Vardareli, E. and Dincer, S. (2004) Occupational Exposure to Hepatitis Infection among Turkish Nurses: Frequency of Needle Exposure, Sharps Injuries and Vaccination. Epidemiology and Infection, 132, 27-33. http://dx.doi.org/10.1017/S0950268803001407

[13] Nejad, S.B., Allegranzi, B., Syed, S.B., Ellis, B. and Pittet, D. (2011) Health-Care-Associated Infection in Africa: A Systematic Review. Bulletin of the World Health Organization, 89, 757-765. http://dx.doi.org/10.2471/BLT.11.088179

[14] Richmond, J.A., Dunning, T.L. and Desmond, P.V. (2007) Health Professionals' Attitudes toward Caring for People with Hepatitis C. Journal of Viral Hepatitis, 14, 624-632. http://dx.doi.org/10.1111/j.1365-2893.2007.00849.X

[15] Joukar, F. and Taherri Ezbarami, Z. (2007) Nursing Student and Staff Knowledge about Nosocomial Infection. Iranian Journal of Infectious Diseases, 12, 83-86.

[16] Tetali, S. and Choudhry, P. (2006) Occupational Exposure to Sharps and Splash: Risk among Health Care Providers in Three Territory Care Hospitals In South India. Indian Journal of Occupational and Environmental Medicine, 10, 3540. http://dx.doi.org/10.4103/0019-5278.22894

[17] Ayed, A., Eqtait, M., Fashafsheh, I. and Ali, G. (2015) Knowledge \& Compliance of Nursing Staff towards Standard Precautions in the Palestinian Hospitals. Advances in Life Science and Technology, 36, 21-30.

[18] Malekmakan, L., Haghpanah, S., Askarian, M., Jowkari, M. and Moalaee, M. (2008) Hand Hygiene in Iranian Health Care Workers. American Journal of Infection Control, 36, 602-603. http://dx.doi.org/10.1016/j.ajic.2008.01.006

[19] McLaws, M.L., Maharlouei, N., Yousefi, F. and Askarian, M. (2012) Predicting Hand Hygiene among Iranian Health 
Care Workers Using the Theory of Planned Behavior. American Journal of Infection Control, 40, 336-339. http://dx.doi.org/10.1016/j.ajic.2011.04.004

[20] Asadollahi, M., Arshadi Bostanabad, M., Jebraili, M., Mahallei, M., Seyyed Rasooli, A. and Abdolalipour, M. (2015) Nurses’ Knowledge Regarding Hand Hygiene and Its Individual and Organizational Predictors. Journal of Caring Sciences, 4, 45-53.

[21] Fashafsheh, I., Ayed, A., Eqtait, F. and Harazneh, L. (2015) Knowledge and Practice of Nursing Staff towards Infection Control Measures in the Palestinian Hospitals. Journal of Education and Practice, 6, 79-90.

[22] Kermode, M., Jolley, D., Langkham, B., Thomas, M.S., Holmes, W. and Gifford, S.M. (2005) Compliance with Universal/Standard Precautions among Health Care Workers in Rural North India. American Journal of Infection Control, 33, 27-33. http://dx.doi.org/10.1016/j.ajic.2004.07.014

[23] Osborne, S. (2003) Influences on Compliance with Standard Precautions among Operating Room Nurses. American Journal of Infection Control, 31, 415-423. http://dx.doi.org/10.1067/mic.2003.68

[24] Gammon, J. and Gould, D. (2005) Universal Precautions. A Review of Knowledge, Compliance and Strategies to Improve Practice. Journal of Research in Nursing, 10, 529-547. http://dx.doi.org/10.1177/136140960501000503

[25] Aniebue, P.N., Aguwa, E.N. and Obi, E.I. (2010) Universal Precautions: Awareness and Practice of Patent Medicines Vendors in Enugu Metropolis, South East Nigeria. Nigerian Medical Journal, 51, 30-34. 